\title{
建筑室内设计中手绘表现的重要性
}

\author{
余鹰 \\ 深圳市居众装饰设计工程有限公司 \\ DOI:10.32629/btr.v2i11.2638
}

[ 摘 要] 手绘是建筑室内设计师需要掌握的基础技能, 其能够通过简单线条的勾勒将设计者的思路及设计方向表述出来, 实现与用户的沟通和 交流。不过现阶段很多设计人员过于依赖计算机及设计软件, 忽略了手绘的重要性, 故而使得建筑室内设计受到阻碍, 无法满足居住者的实际要 求。基于此,本文就对建筑室内设计中手绘表现的重要性进行分析阐述,希望对设计人员有所帮助。

[关键词] 定义; 手绘表现的重要性; 室内设计中手绘表现的具体应用

\section{1 手绘表现的定义}

手绘表现就是设计者利用徒手绘画的方式进行设计理念表现的一种 形式。建筑室内设计的手绘表现技法能够在较短时间内, 将用户的要求及 设计者的理解构思通过绘画的形式直观表述出来, 其虽没有软件制图精细, 但却可将室内空间结构实行合理划分, 简单描述各种家居造型、尺寸, 并统 一调节材质、色彩, 将室内空间的大体效果展现在设计者及用户眼前, 以凸 显整体艺术效果。手绘表现是建筑室内设计的初期阶段, 也是设计内容的 调整阶段, 手绘表现处理的合理性, 对于完善建筑室内设计, 缩短设计时间 有着显著效果。

此外, 随着社会的进步人们对建筑室内设计的要求也在不断提高, 设 计人员不仅要掌握专业设计软件的操作技能, 还需提高自身的手绘表现能 力, 进而快速、清晰的将创意展现在用户眼前, 改进服务品质。

\section{2 建筑室内设计中手绘表现的重要性}

2. 1记录设计者的设计灵感

设计本身就属于一种创造性的活动。在建筑室内设计时, 尤其是初级 阶段, 设计者需要考察现场环境, 并对用户的设计要求予以了解, 在此期间, 设计者需要通过手绘表现的方式对自己即刻的灵感予以及时记录, 之后再 依据勘查中收集到的数据信息, 对设计内容实行深入思考和研究, 完成整 套设计方案。可以说, 手绘是一种较为重要的记录工具, 也是设计中主要的 辅助措施, 其能够快速、准确的记录设计者的所看、所感、所想, 再加上其 绘画场地的随意性, 可以很好的记录设计者的理念和构思, 增强基稿准确 性、合理性, 进而为后续室内设计提供可靠依据。

2. 2 辅助设计师进行分析

\section{4 完善工程施工中的造价控制}

材料控制中, 企业需要制定科学完善的物资采购管理措施, 要求相关人 员严格按照制度执行。在建筑材料采购中, 要以施工图为依据编制工程材料 购进计划, 高度重视书面记录。另外, 材料管理人员需以批准的材料采购计划, 提供工程建设中所需要的材料。施工材料经检验合格后方可进入施工现场。 发放物资时, 需创建物资使用定额制度, 并要求施工人员阐述施工材料用量 过大的原因, 然后采取针对性预防控制措施, 严格监督材料使用环节。施工后 要及时清理现场材料, 做好记录和监测, 及时分析和处理现场发生的问题。

再者, 人工和机械费控制中也应采取量价分离的方式。某一个分项工 程中实际用工量不得大于投标文件中相对应的用工量, 实际施工中总的人 工费不得大于投标文件中的总人工费, 否则应找出原因, 制定纠偏措施。机 械费用主要受台班单价和数量影响。为更好地控制台班费用, 首先, 管理人 员需合理安排施工生产, 制定设施租赁管理计划, 控制设备闲置问题; 其次, 改进机械设备调度使用, 防止窝工问题, 增大机械设备的利用率。再次, 重
建筑室内设计不仅要融合工程学和建筑美学的知识内容, 还应结合室 内空间功能、实用性能及美观性的要求, 进行综合分析和考量, 这样才能保 证建筑室内设计的合理性, 设计方案的可行性。由此, 就需要设计者反复推 敲和完善设计内容, 并对先前的设计构思及架设予以验证, 及时修正和调 整不合理之处, 以满足用户的个性化需求。

手绘表现可以将设计者先前的构思和架设进行记录, 为后续的分析及 推敲提供可靠数据支持。其不仅可以保存先前的各种理论和推断, 方便后 期继续使用, 还可以将设计师分析的过程予以体现, 为下一阶段的工作提 供设计依据, 方便设计师对各种设计的结果进行对比、分析、评估, 从而做 出最佳的设计选择。

\section{3加强交流沟通效果}

在建筑室内设计中, 要想提高设计质量, 设计者之间、设计者与用户之 间就需实行及时的沟通和交流, 让设计者明确设计要求, 及时调整不合理 的设计内容, 这样才能保证设计的合理性、可行性, 满足用户的期望和需 求。但是不同主体之间毕竟存在表达方式、思维能力和专业素质上的差异, 尤其是在设计师与客户之间, 这些差异更明显, 这导致双方对于室内设计 的沟通无法顺利地进行, 双方的交流不够顺畅, 最终对设计成果以及客户 的满意程度产生不良影响。

为此, 设计者应当采取一种更为有效、直观的展现方式来促进双方的 沟通交流, 及时解决设计中存在的问题, 强化设计效果。而手绘则是最为直 观的表现形式, 设计者通过手绘可将自己的设计理念直观的展现在相关人 员眼前, 并通过设计者的讲解, 使用户及其他设计人员明确了解设计的主 体思路, 对最终的设计效果有一个大致的印象, 同时用户可提出设计中不

视工程设备保养维护, 避免出现设备运行异常问题; 最后, 上机人员需与生 产辅助人员建立合作关系, 从而增大台班产量。

\section{4 结束语}

工程造价对工程的经济效益和企业的健康发展有着十分重要的影响, 且工程造价渗透于工程建设的每一个细节。现如今, 我国建筑行业竞争出 现白热化趋势, 建筑企业若想在市场竞争中稳操胜券, 就必须加大造价控 制的力度, 以此降低工程成本, 推动企业的可持续进步。

\section{[参考文献]}

[1]张姗姗.建筑工程造价的影响因素及降低工程造价方法的探讨 [J]. 智能城市,2019,5(18):93-94.

[2]刘立英.工程造价影响因素分析及降低工程造价措施[J].建材与装 饰,2019,(29):111-112.

[3]邴欣.建筑工程造价的影响因素及降低工程造价的对策[J].河南建 材,2019,(04):310-311. 
符合自己要求的地方, 与设计者交流, 然后进行合理的修改, 以此完善设计 方案。设计者利用手绘表现,一方面促进了不同主体之间的交流和沟通, 便于及时解决矛盾和冲突, 促进设计过程的顺利进行; 另一方面可以使设 计方案得到不同角度的考良和检验, 让设计者及时发现设计方案的不足之 处, 并完成改进, 进一步提升设计的科学性和实用性。

\section{3 建筑室内设计中手绘表现的具体应用}

3. 1 项目简介

以某城市 $\mathrm{CBD}$ 商圈中一酒店商业建筑的室内设计为例, 该建筑内部集 餐饮、商务、住宿、休闲等多功能为一体, 是该城市中较为重要的标志性 建筑。

\section{2方案设计阶段}

3.2.1方案初始阶段

初始方案的设计包括设计目标、立意及构思的明确, 准确全面的收集 所需资料信息。

其一, 在资料信息收集中, 需要先对本项目的任务书与用户需求予以 详细了解, 并做好现场前期勘查工作, 明确项目最终建设效果, 掌握重难点 部位, 以提高设计水平。之后在资料信息收集时, 应保证直接资料和间接资 料的全面性、完整性。其中直接资料涵盖人流倾向性路线、活动尺寸预留、 空间功能等内容; 间接资料涵盖了区域文化特征、民宿风情的等信息。另 外, 在资料收集中, 应结合任务书的具体要求, 对设计风格予以综合考虑, 按照设计风格要求进行相关文献资料及网络数据的收集和整理, 以期能够 更好的激发设计者的创作灵感, 为整个设计理念铺陈。

本项目室内设计以中式和法式混合的设计风格为主, 中式风格设计 中需要对宗教信仰、文化生活等内容实行分析和了解, 而法式风格设计 需要对现有的法国元素、装置纹样予以掌握, 并将其融入到中式风格中 来, 如牡丹与卷草纹的融合应用, 可以加强整体空间视觉效果, 营造独特 的感官体验。

其二, 在方案构思中。先要做好全局设计构想, 其中包括设计主题及文 化背景、空间划分及功能、尺寸大小、结构形式及高低变化、功能区域间 的交通线路规划、视觉艺术处理、设计风格、心理感受、材料选用、结构 工艺及成本结算等。只有实行综合考虑分析, 如此才能加强整体图纸设计 的可行性、科学性, 保证最终项目的整体建设效果, 凸显地标性作用。

本项目在方案构思中主要采用了模仿设计的方法,一方面借鉴已有经 验和图示, 如利用屏风完成装饰, 营造文化意境。另一方面通过仿生设计的 应用, 提升空间主题表现效果, 丰富空间内涵。如在设计中应用自然花卉结 构来凸显主题特征, 加强空间协调性; 融入法式浪漫风情, 结合历史文化特 点, 营造雍容华贵之感, 实现中西文化的交融, 突显酒店的整体氛围。

在该环节, 通过手绘图纸的应用, 可对设计框架及方向进行表述, 为设 计者深入分析及想象空间的持续发展提供了帮助, 同时从手绘图纸中也能
够直观的了解设计者思路进程, 掌握设计思路, 便于设计者有效解决设计 中存在的问题, 增强设计的整体性和完善性。在设计中除了要注重空间布 局的合理性外, 还要对空间之间的连接方式予以思考和研究, 以凸显空间 独立性和融合性, 更好的发挥其作用和功效。

\section{2 .2 方案深化阶段}

方案深化阶段是一个由简入难的过程, 不仅涉及的内容较多, 对事物 细节处理也有着较高的要求。该过程中, 需要对空间内各类关系实施有效 处理, 如功能及形式、风格色彩、经济成本等, 并通过及时的沟通和交流, 合理调整和优化方案, 注重室内设计的完善性与科学性。如在空间规划设 计中, 卧室设计在构思阶段, 设计师可能只会对功能及效果予以考虑, 而在 深化阶段, 则需要根据空间使用者自身情况, 综合环境因素实行细致分析, 细化方案内容, 以满足使用者需求。切忌不可盲目跟风, 进而影响空间设计 的效果, 破坏整体氛围。

在方案深化阶段, 手绘表现形式以速写式的空间透视草图或空间界面 图为主。本项目在深化阶段, 利用手绘表现将各节点图进行分析和调整, 并结合工程学相关知识, 合理规划空间尺寸、朝向, 以确保空间内的通风及 采光效果, 营造良好的居住体验。另外, 在深化过程中这些徒手草图还发挥 着拓宽思路、精练构思、确定方案的作用。

\subsection{3方案完善阶段}

方案完善阶段包含设计思维的完善及设计表现图纸的完善两部分内 容。在该阶段内, 手绘表现通过速写式透视草图、空间界面草图及展示型 草图等表现形式, 为方案的调整和优化提供了帮助。本项目在方案完善阶 段, 将手绘表现效果图与电脑制图结合起来, 将手绘图纸中的内容通过电 脑软件实行真实还原, 并对其中存在的不合理尺寸、结构及空间形象予以 合理调整, 确保设计方案的可行性、合理性, 通过软件的渲染, 将最终的设 计效果真实展现在设计者及企业的眼前。可以说, 完善阶段的手绘表现是 按照设计意向进行空间关系、比例关系、色彩关系、搭配关系的描述, 同 时通过不同平面结构图直观的展现出来。

\section{4 结束语}

综上所述, 手绘设计作为建筑室内设计的基础环节, 在室内设计中起 到非常重要的作用。设计者应当不断完善自身的手绘表现技法, 提升室内 设计的综合水平, 加强空间表现效果, 以此满足用户的实际要求, 推动设计 行业的良性发展。

[参考文献]

[1]汪永辉.试论建筑室内设计中手绘表现的重要性及常用材料质感 的表达[J].中国建材科技,2019,(3):57.

[2]彭昭,胡静.论建筑室内设计与手绘效果图表现 [J].现代装饰(理 论),2012,(4):81.

[3]张杰.室内设计手绘表现之我见[J].开封大学学报,2018,32(2):70-72. 